\title{
Effects of Fluorosis and Bleaching on Shear Bond Strengths of Orthodontic Brackets
}

Necdet Adanira, DDS, PhD

Hakan Türkkahraman ${ }^{\text {, }}$ DDS, PhD

Ahmet Yalçın Güngör ${ }^{c}$

\begin{abstract}
Objectives: To evaluate the effects of fluorosis and bleaching on shear bond strengths of orthodontic brackets.

Methods: A total of 45 (30 fluorosed and 15 non-fluorosed) non-carious freshly extracted human permanent premolar teeth which were extracted for orthodontic reasons and without any caries or visible defects were used in this study. Fluorosed teeth were selected according to the modified Thylstrup and Fejerskov index (TFI), which is based on the clinical changes in fluorosed teeth. First group consisted of 15 fluorosed teeth. Second group of fluorosed teeth were bleached with a $35 \%$ hydrogen peroxide office bleaching agent. Third group served as control. No bleaching procedure was applied. Orthodontic brackets were bonded with a light cure composite resin and cured with a halogen light. After bonding, shear bond strengths of the brackets were tested with Universal testing machine.

Results: The results showed that fluorosis only and bleaching of fluorosed teeth significantly reduced the bond strengths of the orthodontic brackets $(P<.001)$. Although bleaching of fluorosed teeth decreased the values more, no statistically significant difference was found between fluorosis group and fluorosis+bleaching group ( $P>.05)$.

Conclusions: Fluorosis and bleaching of fluorosed teeth reduce bracket bond strength to enamel, but the bond strength with these still exceed the minimum 6 to $8 \mathrm{MPa}$ required to expect adequate clinical performance. (Eur J Dent 2007;1:230-235)
\end{abstract}

Key Words: Fluorosis; Bleaching; Shear bond strength; Hydrogen peroxide.

- assistant Professor, Department of Endodontics, Faculty of Dentistry, University of Suleyman Demirel.

b Associate Professor, Department of Orthodontics, Faculty of Dentistry, University of Suleyman Demirel. c Research Assistant, Department of Orthodontics, Faculty of Dentistry, University of Suleyman Demirel.

- Corresponding Author: Dr. Necdet ADANIR S. Demirel Universitesi, Dishekimligi Fakultesi, Endodonti AD., Dogu Kampusu, 32060 Isparta / TURKIYE Tel: + 902462113287 Fax: + 902462370607

E-mail: necdet@dishek.sdu.edu.tr

\section{INTRODUCTION}

Tooth discoloration may be classified as intrinsic, extrinsic, and a combination of both. ${ }^{1}$ Intrinsic discoloration occurs following a change to the structural composition or thickness of the dental hard tissues. Intrinsic tooth discoloration is caused by aging, microcracks in the enamel, tetracycline medication, restoration, dental caries and excessive fluoride ingestion. ${ }^{2}$ Excessive fluoride in drinking water, greater than 1 to 2 ppm, can cause metabolic alteration in the ameloblasts, 
resulting in a defective matrix and improper calsification of teeth. An affected tooth shows a hypomineralized, porous subsurface enamel and acid-resistant well-mineralized surface layer (Figure 1). ${ }^{3}$

Several authors investigated bond strength between composite materials and fluorosed enamel or dentin. ${ }^{4-7} \mathrm{Ng}^{\prime}$ ang'a et al ${ }^{8}$ reported no significant differences in the bond strengths between fluorosed and normal enamel. On the other hand, Weerasinghe et $\mathrm{al}^{7}$ found that severity of fluorosis affects the micro-shear bond strength of a self-etching bonding system to fluorosed enamel. Some investigators have recommended extended enamel conditioning with phosphoric acid when bonding composite resin to the fluorosed enamel to increase bond strength. ${ }^{5,9}$ To date, only limited and contradictory data are available on shear bond strength of brackets to fluorosed human enamel. Thus, further research is needed to clarify these conflicting results.

Patients' increased awareness of esthetic outcomes and their desire to look and feel better about themselves have led to enormous demands on dentists to perform esthetic procedures. Fluorosed teeth can be treated with various restorative techniques, such as direct composite veneers, indirect porcelain veneers, ceramic crowns, microabrasion technique and bleaching. ${ }^{10-}$

13 Effect of bleaching on the bond strength of adhesives to enamel is well documented. However, a consensus has not been reached on the effects of bleaching on bond strengths of brackets. Several authors reported that tooth bleaching reduce the shear bond strength of resin composite materials to enamel or dentin surfaces. ${ }^{14-18}$ In contrast, some authors claimed that bleaching procedures did not affect shear bond strengths. ${ }^{19-21}$ However, to our knowledge, no study evaluated bond strengths of

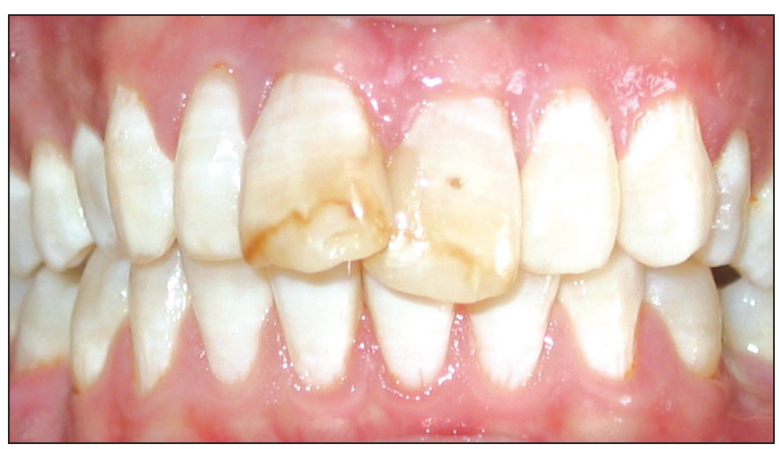

Figure 1. Chalky white appearance of fluorosed teeth. orthodontic brackets to bleached fluorosed teeth.

Therefore, the aim of this invitro study was to evaluate the effects of fluorosis and bleaching of fluorosed teeth on shear bond strengths of orthodontic brackets. Our null hypothesis was that fluorosis and bleaching of fluorosed teeth do not affect shear bond strengths of orthodontic brackets bonded to enamel.

\section{MATERIALS AND METHODS}

A total of 45 (30 fluorosed and 15 non-fluorosed) non-carious freshly extracted human permanent premolar teeth, extracted for orthodontic reasons and without any caries or visible defects, were used in this study. Fluorosed teeth were selected according to the modified Thylstrup and Fejerskov index (TFI), which is based on the clinical changes in fluorosed teeth. ${ }^{22}$ Specific features of teeth with TFI scores of 4 are a marked opacity and a chalky white appearance on the entire surface (Figure 1). Each tooth was individually embedded in auto polymerizing acrylic resin (Meliodent, Herause Kulzer, Hanau, Germanyl. The specimens were kept in distilled water except during the bleaching, bonding and testing procedures. Thirty fluorosed teeth were divided into two groups of 15 each. A group of 15 non-fluorosed teeth (TFI score of 0 ) served as the control group.

Group I (Fluorosis): No bleaching procedures were applied.

Group II (Fluorosis+Bleaching): Teeth were bleached with a $35 \%$ hydrogen peroxide IOpalescence Xtra, Ultradent Products Inc, South Jordan, Utah), exposed to a fast halogen curing light $\left(1000 \mathrm{~mW} / \mathrm{cm}^{2}\right)$ (Blue Swan, Dentanet, Istanbul, Turkeyl for 20 seconds, and left standing for 15 minutes. The gel that had been applied to the tooth was washed away and a fresh gel was reapplied, light activated, left standing for another 15 minutes, and washed away. Before bonding, the teeth were stored in distilled water for 2 days at room temperature.

Group III: Control group.

Before bonding, the facial surfaces of the teeth were cleaned with a mixture of water and pumice. The teeth were rinsed thoroughly with water and dried with oil and moisture-free compressed air. Each tooth was etched with $37 \%$ phosphoric acid gel for 30 seconds. Then, all teeth were rinsed with water/spray combination for 30 seconds and 
dried until characteristic frosty white etched area is observed.

Ormco Mini 2000 (Ormco Corp, Glendora, Calif) bicuspid metal brackets with $9.63 \mathrm{~mm}^{2}$ surface area were used. Light Bond (Reliance Orthodontic Products, Inc., IIl, USAl was used as orthodontic adhesive. With a microbrush, a thin uniform layer of sealant was applied on the etched enamel and cured for 20 seconds. A thin coat of sealant was also painted on the metal bracket base and cured for 10 seconds before applying paste. Using a syringe tip, the paste was applied to bracket base. The bracket was then positioned on the tooth and pressed lightly in the desired position. Excess adhesive was removed with a sharp scaler and cured with a Heliolux DLX (Vivadent ETS, Schaan, Liechtenstein) for 40 seconds (20 seconds on the mesial and 20 seconds on the distal surfaces of the brackets).

All specimens were stored in distilled water at $37^{\circ} \mathrm{C}$ for 24 hours and thermocycled for 500 cycles between $5^{\circ} \mathrm{C}$ and $55^{\circ} \mathrm{C}$, using a dwell time of 30 seconds. Each specimen was loaded into universal testing machine (Lloyd; Fareham, Hants, England) using Nexjen software for testing, with the long axis of the specimen being perpendicular to the direction of the applied force. The standard knife edge was positioned to make contact with the bonded specimen (Figure 2). Bond strength was determined in the shear mode at a crosshead speed of $0.5 \mathrm{~mm} / \mathrm{min}$ until fracture occurred. Values of failure loads (N) were recorded and converted into megapascals (MPa) by dividing the failure load $(\mathrm{N})$ by the surface area of the bracket base $\left(9.63 \mathrm{~mm}^{2}\right.$ ).

After debonding, all teeth and brackets in the test groups were examined under 10x magnification. Any adhesive remained after debonding was assessed and scored according to the modified Adhesive Remnant Index (ARI). ${ }^{23}$ The scoring criteria of the index are as follows:

$1=$ All of the composite, with an impression of the bracket base remained on the tooth;

$2=$ More than $90 \%$ of the composite remained on the tooth;

$3=$ More than $10 \%$ but less than $90 \%$ of the composite remained on the tooth;

$4=$ Less than $10 \%$ of composite remained on the tooth;

$5=$ No composite remained on the tooth.

\section{Statistical analysis}

Descriptive statistics, including the mean, standard deviation, standard error, minimum and maximum values were calculated for each of the groups tested. One-way analysis of variance (ANOVA) and Tukey multiple comparison tests were used to compare shear bond strengths of the groups. The chi-square test was used to determine significant differences in the ARI scores among test groups. Significance for all statistical tests was predetermined at $P<.05$. All statistics were performed with SPSS version 11.0.0 (SPSS Inc., Chicago, IL, USA).

\section{RESULTS}

The descriptive statistics on the shear bond strengths (MPa) of the groups are presented as boxplots in Figure 3. All groups displayed clinically acceptable mean bond strengths lover $8 \mathrm{MPa}$ ). Analysis of variance (ANOVA) indicated a significant difference between groups $(P<.001)$ (Table 1). Highest values of shear bond strengths were measured in Group III (control). Shear bond strengths in Groups I and II were significantly lower than Group III ( $P<.001)$. No significant difference was found between Group I and Group II (P>.05).

Frequency distribution of the ARI scores and the chi-square comparison of the test groups are presented in Table 2. There was no significant difference between groups. There was a greater frequency of ARI scores of 3,4 and 5 in Group II (Fluorosis+Bleaching), which indicated that failures in this group were mainly in the enameladhesive interface.

\section{DISCUSSION}

This study was designed to evaluate the effects of fluorosis and bleaching of fluorosed teeth on shear bond strengths of orthodontic brackets. For this purpose, fluorosed teeth (TFI score 4) were collected and selected by two examiner's agreement (N.A, H.T). Since fluoride content can vary between different teeth, only fluorosed human maxillary premolar teeth were used in this study.

In our study, all specimens were etched with $37 \%$ phosphoric acid gel for 30 seconds. Then, all teeth were rinsed with water/spray combination for 30 seconds and dried until characteristic frosty white etched area is observed. Some investigators have recommended extended enamel conditioning 
with phosphoric acid when bonding composite resin to the fluorosed enamel.5,9 However, AlSugair and Akpata $^{24}$ demonstrated in an in vitro study that the mean depth of enamel dissolutions were not significantly different for the enamel specimens between non-fluorosed (TFI Score 0)

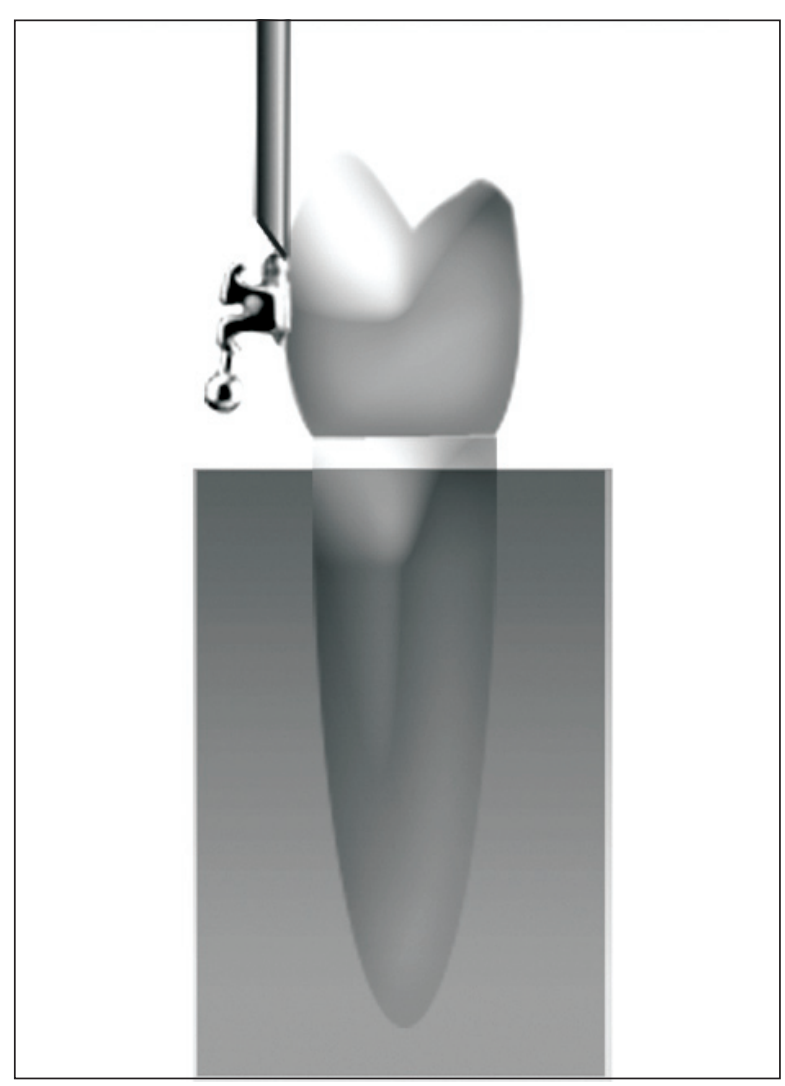

Figure 2. Schematic representation of the specimen in the test machine. The standard knife edge was positioned to make contact with the bonded specimen and directed parallel to the long axis of the crown of the tooth. and fluorosed teeth (TFI score 4) etched for 30 seconds. Therefore, we did not extend etching time as was done by Ateyah and Akpata ${ }^{5}$ and Opinya and Pameijer?.

The findings of the present study demonstrate that fluorosis significantly reduced the shear bond strengths of the brackets to enamel. The mean shear bond strength of the fluorosed teeth group was $13.94 \pm 3.24 \mathrm{MPa}$, while the control group was $19.29 \pm 4.71 \mathrm{MPa}$. This result is consistent with Weerasinghe et $\mathrm{al}^{7}$ who reported that severity of fluorosis affected the micro-shear bond strength

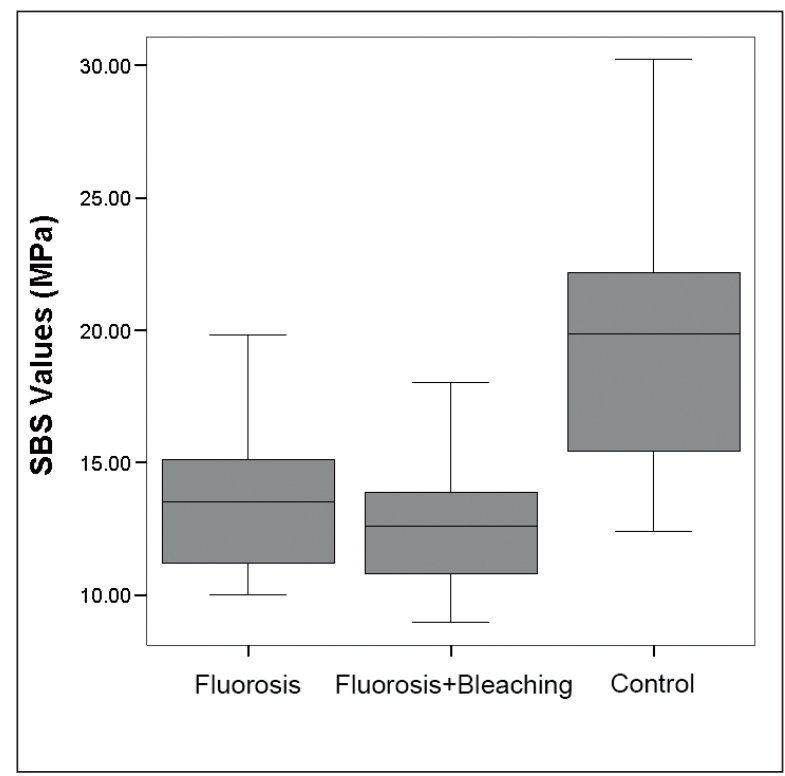

Figure 3. Shear bond strengths (MPa) of the groups. Results presented as boxplots. Horizontal line in middle of each boxplot shows median value; horizontal lines in box indicate $25 \%$ and $75 \%$ quartiles; lines outside box indicate $5 \%$ and $95 \%$ quartiles.

Table 1. The results of the analysis of variance (ANOVA) comparing the shear bond strengths of the groups.

\begin{tabular}{ccccccccccc}
\hline \multicolumn{1}{c}{ Group I } & \multicolumn{9}{c}{ Group II } & \multicolumn{2}{c}{ Group III } \\
\hline \multicolumn{2}{c}{ (Fluorosis) } & \multicolumn{2}{c}{ (Fluorosis+Bleaching) } & \multicolumn{2}{c}{ (Control) } & \multicolumn{3}{c}{ Post-hoc tests } \\
\hline Mean & Sd & Mean & Sd & Mean & Sd & Sig. & I-II & I-III & II-III \\
\hline 13.94 & 3.24 & 12.57 & 2.34 & 19.29 & 4.71 & $0.000^{* * *}$ & ns & $* * *$ & $* * *$ \\
\hline
\end{tabular}

ns: non-significant, ${ }^{* * *}: \mathrm{P}<.001$

Table 2. Frequency distribution of the Adhesive Remnant Index (ARI) scores and the Chi-Square comparison of the test groups.

\begin{tabular}{lllllllll}
\hline & \multicolumn{1}{c}{ ARI Scores } & & & Test \\
\hline Test Groups & 1 & 2 & 3 & 4 & 5 & $\mathrm{n}$ & ns \\
\hline Group I (Fluorosis) & 2 & 5 & 6 & 0 & 2 & 15 & \\
Group II (Fluorosis+Bleaching) & 3 & 1 & 5 & 4 & 2 & 15 & 15 & \\
Group III (Control) & 3 & 5 & 4 & 1 & 2 & & \\
\hline
\end{tabular}

ns: non-significant 
of a self-etching bonding system to fluorosed enamel. Their study also revealed that severe fluorosis decreased the shear bond strength even with the traditional acid etching using 37\% phosphoric acid.

Fluorosed teeth have the highest concentration of fluoride in the outer $200 \mu \mathrm{m}$ of enamel surface. ${ }^{5}$ Weerasinghe et $\mathrm{al}^{7}$ removed this hypermineralized, acid resistant enamel surface before the shear test. Since this procedure is not suitable for orthodontic practice, we did not remove the enamel surface layer in our study.

In contrast to the present study, $\mathrm{Ng}^{\prime}$ ang'a et $\mathrm{al}^{8}$ found no statistically significant difference between the mean values for bond strength of orthodontic brackets in fluorosed and non-fluorosed teeth. They bonded brackets with a composite resin after over-etching the enamel surface with $40 \%$ phosphoric acid for 60 seconds. The result of their study revealed that fluorosis decreased the bond strength compared with non-fluorosed teeth. However, the difference between the means for bond strength was not statistically significant.

With the increasing number of adult patients seeking orthodontic treatment, orthodontists may face bonding brackets to previously bleached fluorosed teeth. Up to date, no data was available concerning shear bond strength of brackets to bleached fluorosed enamel. Therefore, we aimed to investigate not only the effect of fluorosis, but also bleaching procedure on shear bond strength of orthodontics brackets on fluorosed enamel surface. In the present study, mean shear bond strength for fluorosis+bleaching group was $12.57 \pm 2.34 \mathrm{MPa}$ that was the lowest in all groups. These results are in agreement with Nour El-din et $\mathrm{al}^{16}$, Titley et $\mathrm{al}^{25}$ and Dishman et $\mathrm{al}^{26}$ who also reported reduced bond strengths after bleaching procedure. Nour El-din et $\mathrm{al}^{16}$ investigated the shear bond strength, degree of resin infiltration and failure mode when organic solvent-based adhesives were used in immediate bonding to enamel bleached with $10 \%$ carbamide peroxide or $38 \%$ hydrogen peroxide systems. The shear bond strengths of $38 \%$ hydrogen peroxide and $10 \%$ carbamide peroxide were significantly lower compared to the non-bleached controls. Moreover, scanning electron microscopy revealed few, thin and fragmented resin tags when $38 \%$ hydrogen peroxide and $10 \%$ carbamide peroxide were used.
On the other hand, Bishara et $\mathrm{al}^{21,27}$ reported that in-office bleaching and at-home bleaching did not affect the shear bond strength of orthodontic brackets to enamel. Uysal et $\mathrm{al}^{20}$ suggested that office bleaching with hydrogen peroxide did not adversely affect the bond strengths of brackets bonded immediately after bleaching or 30 days after bleaching. Our results agree with Nour El-din $\mathrm{al}^{16}$, however contradicting the results of Uysal et $\mathrm{al}^{20}$ and Bishara et al's ${ }^{21}$. The lowest values obtained in fluorosis+bleaching group may be explained with bleaching induced morphological alterations in the most superficial enamel crystallites. The bleaching agents significantly decrease the calcium and phosphate content of the enamel. ${ }^{28,29}$ In addition, residual oxygen in the enamel pores may interfere with resin infiltration into ename ${ }^{30}$ or inhibit polymerization of the resin. ${ }^{31}$

It must be emphasized that this study was performed in vitro. Therefore, shear bond strengths obtained in this study may not correspond well with clinical success. Further in vivo studies are still needed to substantiate the results obtained in this study.

\section{CONCLUSIONS}

- Enamel fluorosis significantly decreased the bond strength of orthodontic brackets.

- Although bleaching of fluorosed enamel decreased the bond strengths more, the difference between fluorosis+bleaching and fluorosis groups was not statistically significant.

- Though fluorosis and bleaching of fluorosed teeth reduce bracket bond strength to enamel, the bond strength with these still exceed the minimum 6 to $8 \mathrm{MPa}$ required to expect adequate clinical performance.

\section{REFERENCES}

1. Hattab FN, Qudeimat MA, al-Rimawi HS. Dental discoloration: an overview. J Esthet Dent 1999;11:291-310.

2. Watts $A$, Addy $M$. Tooth discolouration and staining: a review of the literature. Br Dent $J$ 2001;190:309-315.

3. Haywood VB, Berry TG. Natural tooth bleaching. In: Summitt JB, Rabbins JW, Schwartz RS, editors. Fundamentals of operative dentistry: a contemporary approach. Chicago: Quintessence Publishing Co Inc; 2001. p. 402.

4. Awliya WY, Akpata ES. Effect of fluorosis on shear bond strength of glass ionomer-based restorative materials to dentin. J Prosthet Dent 1999;81:290-294. 
5. Ateyah N, Akpata ES. Factors affecting shear bond strength of composite resin to fluorosed human enamel. Oper Dent 2000;25:216-222.

6. Ermis RB, Gokay N. Effect of fluorosis on dentine shear bond strength of a self-etching bonding system. $J$ Oral Rehabil 2003;30:1090-1094.

7. Weerasinghe DS, Nikaido T, Wettasinghe KA, Abayakoon JB, Tagami J. Micro-shear bond strength and morphological analysis of a self-etching primer adhesive system to fluorosed enamel. J Dent 2005;33:419-426.

8. Ng'ang'a PM, Ogaard B, CruZ R, Chinidia ML, Aastrum $E$. Tensile bond strength of orthodontic brackets bonded directly to fluorotic and nonfluorotic teeth: an in vitro comparative study. Am $J$ Orthod Dentofacial Orthop 1992;102:244-250.

9. Opinya $\mathrm{GN}$, Pameijer $\mathrm{CH}$. Tensile bond strength of fluorosed Kenyan teeth using the acid etch technique. Int Dent J 1986;36:225-229.

10. Lynch CD, McConnell RJ. The use of microabrasion to remove discolored enamel: a clinical report. J Prosthet Dent 2003;90:417-419

11. DeliperiS, CongiuMD, BardwellDN. Integration of composite and ceramic restorations in tetracycline-bleached teeth: a case report. J Esthet Restor Dent 2006;18:126-134.

12. Bloom DR, Padayachy JN. Aesthetic changes with four anterior units. Br Dent J 2006;200:135-138.

13. Amato M, Scaravilli MS, Farella M, Riccitiello F. Bleaching teeth treated endodontically: long-term evaluation of a case series. $J$ Endod 2006;32:376-378.

14. Oltu U, Gurgan S. Effects of three concentrations of carbamide peroxide on the structure of enamel. J Oral Rehabil 2000;27:332-340.

15. Shinohara MS, Peris AR, Pimenta LA, Ambrosano GM. Shear bond strength evaluation of composite resin on enamel and dentin after nonvital bleaching. $J$ Esthet Restor Dent 2005;17:22-29; discussion 29.

16. Nour El-din AK, Miller BH, Griggs JA, Wakefield C. Immediate bonding to bleached enamel. Oper Dent 2006;31:106-114

17. Bulut $H$, Turkun $M$, Kaya AD. Effect of an antioxidizing agent on the shear bond strength of brackets bonded to bleached human enamel. Am J Orthod Dentofacial Orthop 2006;129:266-272.

18. Türkkahraman H, Adanir N, Güngör AY. Bleaching and desensitizer application effects on shear bond strengths of orthodontic brackets. Angle Orthod 2007;77:489-493.

19. Sung EC, Chan SM, Mito R, Caputo AA. Effect of carbamide peroxide bleaching on the shear bond strength of composite to dental bonding agent enhanced enamel. J Prosthet Dent 1999;82:595-599.
20. Uysal T, Basciftci FA, Usumez S, Sari Z, Buyukerkmen A. Can previously bleached teeth be bonded safely? Am J Orthod Dentofacial Orthop 2003;123:628-632.

21. Bishara SE, Oonsombat C, Soliman MM, Ajlouni R, Laffoon JF. The effect of tooth bleaching on the shear bond strength of orthodontic brackets. Am J Orthod Dentofacial Orthop 2005;128:755-760

22. Fejerskov 0, Larsen MJ, Richards A, Baelum V. Dental tissue effects of fluoride. Adv Dent Res 1994;8:15-31.

23. Olsen ME, Bishara SE, Damon P, Jakobsen JR. Evaluation of Scotchbond Multipurpose and maleic acid as alternative methods of bonding orthodontic brackets. Am J Orthod Dentofacial Orthop 1997;111:498-501.

24. Al-Sugair MH, Akpata ES. Effect of fluorosis on etching of human enamel. J Oral Rehabil 1999;26:521-528.

25. Titley KC, Torneck CD, Ruse ND, Krmec D. Adhesion of a resin composite to bleached and unbleached human enamel. J Endod 1993;19:112-115.

26. Dishman MV, Covey DA, Baughan LW. The effects of peroxide bleaching on composite to enamel bond strength. Dent Mater 1994;10:33-36.

27. Bishara SE, Sulieman AH, Olson M. Effect of enamel bleaching on the bonding strength of orthodontic brackets. Am J Orthod Dentofacial Orthop 1993;104:444-447.

28. Ruse ND, Smith DC, Torneck CD, Titley KC. Preliminary surface analysis of etched, bleached, and normal bovine enamel. J Dent Res 1990;69:1610-1613.

29. Perdigao J, Francci C, Swift EJ, Ambrose WW, Lopes M. Ultra-morphological study of the interaction of dental adhesives with carbamide peroxide-bleached enamel. $\mathrm{Am}$ J Dent 1998;11:291-301.

30. McGuckin RS, Thurmond BA, Osovitz S. Enamel shear bond strengths after vital bleaching. Am J Dent 1992;5:216-222.

31. Rueggeberg FA, Margeson DH. The effect of oxygen inhibition on an unfilled/filled composite system. $J$ Dent Res 1990;69:1652-1658. 